\title{
The use of Delfino digital signal controller in power inverter
}

\author{
Krzysztof Górecki ${ }^{1, *}$ \\ ${ }^{1}$ Opole University of Technology, Faculty of Electrical Engineering, ul. Prószkowska 76, 45-758 Opole, Poland
}

\begin{abstract}
This article analyzes the implementation of control algorithm for a single-phase power inverter using digital signal controller (DSC). For this purpose, a floating-point digital signal controller with a trigonometric math unit was used. The controller's task was to control the H-bridge through a dedicated driver for power MOSFET transistors. For this task, transistors made in NexFET technology with low channel resistance were used. The H-bridge is the main power device of a single-phase, two-level power inverter powered by a $12 \mathrm{~V}$ battery. As a modulation method, regular modulation with carrier signal using a triangular signal was used. The main aim was to show the digital signal controller's performance in realtime control of power inverters and to present the maximum sampling frequency of the inverter that can be obtained for the example having been analyzed.
\end{abstract}

\section{Introduction}

In recent years, many new families and architectures of microcontrollers have been created. In particular, the development of 32-bit microcontrollers in applications in power electronics is noticeable. The beginnings dedicated to the power electronics of microcontrollers can be seen in the Texas Instruments TMS320F2xxx family. Originally it was a family included in the group of digital signal processors. These were not the fastest processors, but their advantage was the internal program memory (Flash Eprom) and the peripherals used by Power electronics. The series of these microcontrollers has been called Digital Signal Controllers (DSC). Microchip was the first to introduce this name for its 6000 series microcontrollers. In the case of Texas Instruments, this group includes the TMS320F28x series. The TMS320F28x CPU is 32-bit fixed point processor. This device draws from the best features of digital signal processors and reduced instruction set computing and modified Harvard architecture. The CPU has atomic instructions. It means that CPU can read instructions and data and writes results in single-cycle operation across the pipeline. A specific series of digital signal controllers is a group called Delfino, which in its construction has F28x CPU floating point unit (FPU) and trigonometric math unit (TMU)/Viterbi complex math unit (VCU-II). These series have the Control Law Accelerator (CLA). It is an independent 32-bit floating point math processor for reading ADC samples "just-in-time". This unit works parallel and can work as a preprocessing unit for main CPU. This series has some important peripherals for power electronics. It has many flexible PWM modules with many modes. Delfino TMS320F2837xS are the first single-core DSCs in the industry to offer four 16-bit analog to digital converters, enabling precision measurement in power control applications.
Combination of $\mathrm{C} 28 \mathrm{x}$ and fast CLA provides 400 MIPS of floating-point performance. This features in connection with power control peripherals is powerful tool for power electronic devices [1]. Therefore the controller TMS320F28377S for single-phase off grid power inverter construction was used.

\section{The implementation of control algorithm}

A two-phase grid off single-phase inverter was analyzed. As a modulation method, it uses regular modulation of the carrier signal using a triangular waveform [2-3]. An illustrative drawing of this method is presented in the Fig. 1. On the basis of intersections of a triangular waveform with a sinusoidal controller generates four PWM signals controlling the power MOSFET transistors (NexFET: CSD18532): HOA, LOA, HOB, LOB (Fig. 2).

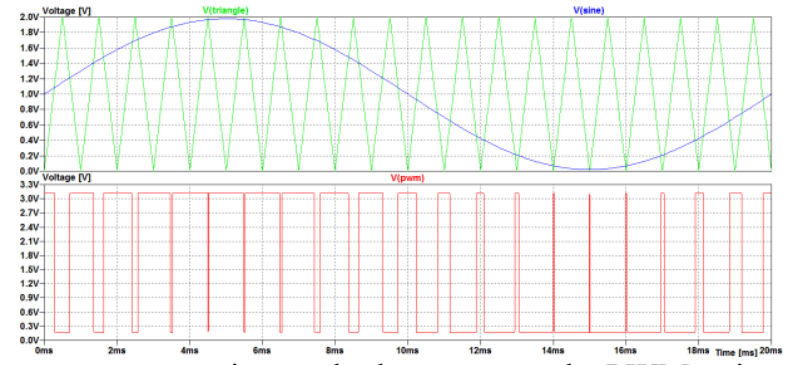

Fig. 1. Intersective method to generate the PWM train corresponding to given signal.

There is also a dedicated driver between the controller and the transistors, which corrects the control signals to accelerate the switching times of the transistors. It was presented in article [4]. It was assumed that the algorithm for calculating width of PWM signal should be executed in real time. The basics of this algorithm are

Corresponding author: k.gorecki@po.opole.pl 
presented in the article [4]. In the case of this inverter, some changes were made, namely the sinusoidal waveform and the triangular waveform were shifted to the area of positive numbers.

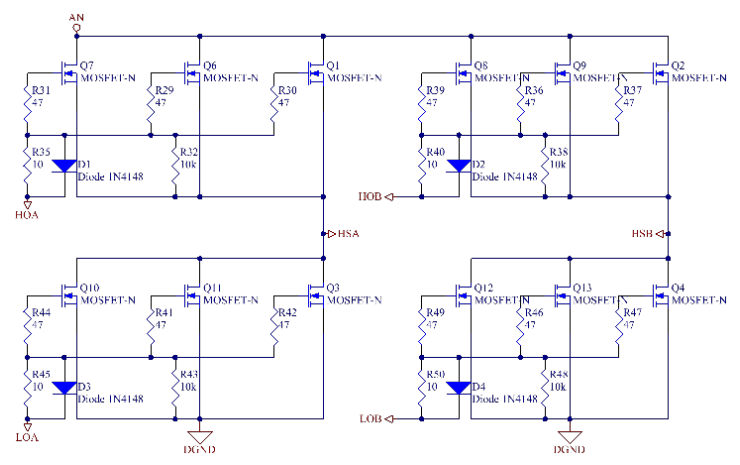

Fig. 2. H-bridge of single-phase power inverter.

This allowed to avoid zero crossing in the calculation. Calculation of the intersection points of these functions is the most important calculation task of the controller. This is due to the presence of the trigonometric function sine. For the first period of the triangular signal from the value 0 , we increase the value of the linear function $F_{\Delta}$ by the value of $\Delta y$ up to the moment of equating with the value of the sinusoidal function $F_{\text {sin }}$. This process uses discrete method. The time value is increased by the sampling period $\Delta t$ and at the same time the value of the sine function and the linear function for the rising part of the half period of the triangular waveform is calculated for a given time value. The number of sampling steps is counted until the functions are equalized. The comparison error should be less than $\Delta y$. This value equals the increase of the $F_{\Delta}$ function when the time is changed by the sampling period $\Delta t$. The algorithm calculates the modulation depth based on the value of the output voltage. It will allow to stabilize the output voltage when the load changes. The carrier frequency was $T_{c}=20 \mathrm{kHz}$, which gives 400 periods of a triangular waveform in one period of a sinusoidal waveform with a fundamental frequency $f=50 \mathrm{~Hz}$. The task that was set for the digital signal controller is to generate such PWM signals that control the transistors, which at the output of the $\mathrm{H}$ bridge (HSA and HSB lines) after filtering out will give a sinusoidal signal with a frequency $50 \mathrm{~Hz}$. In addition, this signal is transformed to a higher voltage, since the input voltages on transistors come from a $12 \mathrm{~V}$ battery. As a result of filtration and voltage increase, a sinusoidal voltage of $230 \mathrm{~V}$ with a frequency of $50 \mathrm{~Hz}$ is obtained. The program implementing the PWM signal generation in the main program of the DSC initialized the basic operating parameters of individual peripherals and the calculations and update of the PWM signal parameters took place in the interruption from the PWM module. This interruption is executed every $50 \mu \mathrm{s}$. For this code structure, the number of cycles and execution times of the code responsible for calculating and updating registers related to the PWM outputs were measured. For the above-described algorithm with division into four quadrants of the sinusoidal period, the measurements of calculation times for the
TMS320F28377S (100MHz) controller was performed for 5 levels of compiler optimization and without optimization: 0-register optimization, 1-local opt., 2 global opt., 3- interprocedure opt., 4-whole program opt. The results of calculation times and the number of instruction cycles are presented in Table 1. The calculation times and instruction cycles of the changed algorithm are similar to those given in [4]. In the case of lack of optimization and register optimization, the values are slightly higher and in the case of other optimizations are slightly smaller.

Table 1. The execution time and cycles of PWM calculations.

\begin{tabular}{|c|c|c|c|}
\hline $\begin{array}{c}\text { Optimization } \\
\text { level }\end{array}$ & \multicolumn{2}{|c|}{$\begin{array}{c}\text { PWM } \\
\text { calculations }\end{array}$} & $\begin{array}{l}\text { TMS320 } \\
\text { F28377S }\end{array}$ \\
\hline \multirow[t]{2}{*}{ No optimization } & \multicolumn{2}{|c|}{ cycles } & 329 \\
\hline & time & $\mu \mathrm{s}$ & 3.29 \\
\hline \multirow[t]{2}{*}{ Opt. level 0} & \multicolumn{2}{|c|}{ cycles } & 276 \\
\hline & time & $\mu \mathrm{s}$ & 2.76 \\
\hline \multirow[t]{2}{*}{ Opt. level 1} & \multicolumn{2}{|c|}{ cycles } & 285 \\
\hline & time & $\mu \mathrm{s}$ & 2.86 \\
\hline \multirow[t]{2}{*}{ Opt. level 2} & \multicolumn{2}{|c|}{ cycles } & 285 \\
\hline & time & $\mu \mathrm{s}$ & 2.86 \\
\hline \multirow[t]{2}{*}{ Opt. level 3} & \multicolumn{2}{|c|}{ cycles } & 285 \\
\hline & time & $\mu \mathrm{s}$ & 2.86 \\
\hline \multirow[t]{2}{*}{ Opt. level 4} & \multicolumn{2}{|c|}{ cycles } & 285 \\
\hline & time & $\mu \mathrm{s}$ & 2.86 \\
\hline
\end{tabular}

\section{CONCLUSION}

The calculation possibilities of the Delfino TMS320F28377S controller are presented above on the example of an application that is a single-phase twolevel power inverter. The results show that for the carrier frequency $\mathrm{T}_{\mathrm{c}}=20 \mathrm{kHz}$ it is possible to work the microcontroller in real time with variable modulation depth with a significant time reserve. The calculation time was less than $6 \%$ of the time between interrupts. These results show that it is possible to implement higher harmonic measurements in real time while increasing the carrier frequency. This will allow to minimize the higher harmonics at the output. Replacing a large iron transformer increasing the voltage with a push-pull converter will be the next step.

\section{References}

1. M. Zygmanowski, B. Grzesik, Space Vector Modulation for 3-level neutral-point clamped inverter using DSP TMS 320F2812, Zeszyty Naukowe. ELEKTRYKA, Politechnika Śląska, VOL. z. 198, pp. 155-166, 2006.

2. D. G. Holmes, T. A. Lipo, Pulse Width Modulation for Power Converters, Principles and Practice, Wiley-Interscience and IEEE Press, 2003.

3. Z. Nowacki Z., Modulacja szerokości impulsów w napędach przeksztaltnikowych prądu przemiennego, Warszawa, PWN, 1991.

4. K. Górecki, Analiza zastosowania kontrolerów sygnatowych $w$ falownikach jednofazowych $z$ tranzystorami NEXFET, XXIV Konf. Nauk. ZKwE'2019, Poznań, 15 kwietnia 2019. 